Article

\title{
Application of Fenton Method for the Removal of Organic Matter in Sewage Sludge at Room Temperature
}

\author{
Yan-Jhang Chen ${ }^{1}$, Tang-Yu Fan ${ }^{1}$, Li-Pang Wang ${ }^{1, *}$, Ta-Wui Cheng ${ }^{2}$, Shiao-Shing Chen ${ }^{1} \mathbb{C}$, \\ Min-Hao Yuan ${ }^{3}$ and Shikun Cheng ${ }^{4, *}$ \\ 1 Institute of Environmental Engineering and Management, College of Engineering, National Taipei \\ University of Technology, Taipei 10608, Taiwan; john11315080@gmail.com (Y.-J.C.); \\ tonyfan08@gmail.com (T.-Y.F.); f10919@ntut.edu.tw (S.-S.C.) \\ 2 Institute of Mineral Resources Engineering, College of Engineering, National Taipei University of \\ Technology, Taipei 10608, Taiwan; twcheng@ntut.edu.tw \\ 3 Department of Occupational Safety and Health, College of Public Health, China Medical University, \\ Taichung 40402, Taiwan; mhyuan@mail.cmu.edu.tw \\ 4 School of Energy and Environmental Engineering, Beijing Key Laboratory of Resource-oriented Treatment of \\ Industrial Pollutants, University of Science and Technology Beijing, Beijing 100083, China \\ * Correspondence: kuniwang@ntut.edu.tw (L.-P.W.); chengshikun@ustb.edu.cn (S.C.); Tel.: +886-2-2771-2171 \\ (ext. 4126) (L.-P.W.); +86-10-6233-4378 (S.C.); Fax: +886-2-8773-2954 (L.-P.W.); +86-10-6233-4378 (S.C.)
}

Received: 30 December 2019; Accepted: 17 February 2020; Published: 18 February 2020

\begin{abstract}
Cement is the most widely used construction material in the world. However, its manufacture is high energy consumption and high carbon emission owing to the high temperature calcination process. Geopolymer is an ideal alternative material for cement because it has a similar structure and performance to cement. In addition, it can be synthesized at room temperature and thus has the advantages of energy saving and carbon emission reduction. Sewage sludge (SS) can be used as raw material for geopolymer synthesis. However, the high organic matter content in SS lowers the mechanical strength of geopolymer. Although the organic matter in SS can be removed by incineration at high temperature, this consumes energy and emits carbon dioxide, which diminishes the advantages of geopolymer. In this study, the Fenton method was applied for the removal of organic matter in SS at room temperature. The parameters of the Fenton method, including the dosages of hydrogen peroxide $\left(\mathrm{H}_{2} \mathrm{O}_{2}\right)$ and $\mathrm{Fe}^{2+}$ reagent $\left(\mathrm{FeSO}_{4} \cdot 7 \mathrm{H}_{2} \mathrm{O}\right)$, reaction time, and initial $\mathrm{pH}$ value, were investigated. The results indicated that $83.7 \%$ of the organic matter in SS could be removed at room temperature by using $5.15 \mathrm{M} \mathrm{H}_{2} \mathrm{O}_{2}$ and $5.15 \mathrm{mM} \mathrm{FeSO}_{4} \cdot 7 \mathrm{H}_{2} \mathrm{O}$ at $\mathrm{pH}$, which suggested the possibility of sewage sludge reclamation through geopolymer synthesis as an alternative material for cement toward sustainability.
\end{abstract}

Keywords: sewage sludge; organic matter; removal; Fenton method; geopolymer

\section{Introduction}

Cement is made from limestone, clay, silica sand, and iron slag. They are ground and mixed with appropriate ingredients, followed by sintering in a rotary kiln at high temperature to become clinker, which is then ground with an appropriate amount of gypsum. Cement is the most widely used construction materials in the world. However, the production and processing of cement consume a high amount energy and cause high carbon dioxide emissions [1].

Geopolymer is thought of as an ideal alternative material for cement because it has a similar structure and performance to cement. In addition, it can be synthesized at room temperature and thus 
has the advantages of energy saving and carbon emission reduction. Geopolymer can be synthesized by solid wastes containing silicon and aluminum, such as fly ash, slag, sewage sludge (SS), etc. [2]. Through the activation by a strong alkali, it is possible to form a structure that is chemically and structurally similar to cement. In addition, geopolymer can solidify heavy metals and thus is an environmentally friendly building material. Generally, raw materials containing high contents of silicon ( $\mathrm{Si}$ ) and aluminum ( $\mathrm{Al}$ ) can be used for the synthesis of geopolymer, such as blast furnace stone powder [3], met-kaolin and volcanic ash [4], coal-fired fly ash [5], and reservoir sludge [6].

On the other hand, sewage sludge (SS) also has high contents of Si and $\mathrm{Al}$ and thus can also be used as a raw material for geopolymer synthesis. However, the high organic matter content in SS lowers the mechanical strength of the synthesized geopolymer. Several treatment methods have been researched to remove the organic matter in SS, including anaerobic digestion, gasification, pyrolysis, supercritical water processing, and incineration $[7,8]$. Recently, the removal of organic matter in SS is mainly treated by incineration due to its convenience. However, the incineration method usually needs to be carried out at a high temperature of $1000^{\circ} \mathrm{C}$, which consumes much energy and emits large amounts of carbon dioxide, thus diminishing the advantages of geopolymer. For the sustainable reclamation of SS as a raw material of geopolymer, the removal of organic matter in SS at room temperature is required.

The Fenton method has been widely investigated for the treatment of organic wastewater streams such as textiles [9,10], pharmaceuticals [11,12], olive mill [13,14], leachate [15], agrochemicals [16,17], etc. In addition, the Fenton method has also been proposed as an environmental friendly approach for the conditioning, dewatering, and filtration of SS. Neyens et al. claimed that at an initial $\mathrm{pH}$ value of 3, and with the dosages of $1.67 \mathrm{mg} \mathrm{Fe}{ }^{2+} / \mathrm{g}$ dry solid (DS) and $25 \mathrm{mg} \mathrm{H}_{2} \mathrm{O}_{2} / \mathrm{g}$ DS, the water content of SS can be reduced to $47 \%$, considering Fenton's reagent $\left(\mathrm{H}_{2} \mathrm{O}_{2}\right.$ and $\left.\mathrm{Fe}^{2+}\right)$ as a chemical conditioner for SS [18]. The Fenton reaction was also proposed to enhance the SS cake dewaterability through the mechanism of degrading extracellular polymeric substances (EPS) which contained a large amount of water [19]. Lu et al. reported that within the initial $\mathrm{pH}$ value range from 2 to 7 , the Fenton reaction appeared to have insignificant effects on filtration efficiency and had a minor effect on the moisture of SS cake [20]. Tony et al. reported that under the conditions of $\mathrm{Fe}^{2+} / \mathrm{H}_{2} \mathrm{O}_{2}=20 / 125 \mathrm{mg} / \mathrm{g} \mathrm{DS}$ and $\mathrm{pH} 6$, the considerable effectiveness of the highest reduction efficiency of capillary suction time (CST) could be achieved [21]. Liu et al. reported that under the optimal conditions of $\mathrm{pH} 5, \mathrm{Fe}^{2+}=40 \mathrm{mg} / \mathrm{g}$ DS, $\mathrm{H}_{2} \mathrm{O}_{2}=32 \mathrm{mg} / \mathrm{g}$ DS, a specific resistant to filtration reduction efficiency of $95 \%$ was achieved in the process of applying SS as the skeleton builder [22]. Liu et al. and Hu et al. both combined Fenton's reagent and lime for the conditioning of SS $[23,24]$. Yu et al. reported less necessity of initial acidification of Fenton conditioning and the $\mathrm{pH}$ of the final filtrate was $6.6 \pm 0.2$ [24]. Most of the previous studies on wastewater treatment emphasized the initial $\mathrm{pH}$ should be an important parameter. However, they did not make a consistent conclusion on the optimal initial $\mathrm{pH}$ value in SS conditioning using Fenton's reagents. Regarding the issue of hazardous waste in SS, Dewil et al. proposed that alkaline thermal hydrolysis and Fenton's peroxidation can reduce the heavy metal content of waste activated sludge by degrading the EPS. A significant reduction on several heavy metals was confirmed [25]. Zhu et al. also reported that combined bioleaching and Fenton-like reaction using the catalyst of $\mathrm{Fe}^{2+}$ by iron-oxidized bacteria and an optimal $\mathrm{H}_{2} \mathrm{O}_{2}$ dosage of $5 \mathrm{~g} / \mathrm{L}$, the removal of $\mathrm{Cu}, \mathrm{Zn}, \mathrm{Pb}$, and $\mathrm{Cd}$ reached $75.3 \%, 72.6 \%$, $34.5 \%$, and $65.4 \%$, respectively [26]. In addition, Wen et al. reported that at an initial pH of 2.5-3.0, a molar ratio of $\mathrm{Fe}^{2+} / \mathrm{H}_{2} \mathrm{O}_{2}=0.1 \sim 0.4$, and $\mathrm{a}_{2} \mathrm{O}_{2}$ dosage of $20 \mathrm{mmol} / \mathrm{L}$, a radical-induced SS Fe nanoparticles (Fe NPs) was made to be the catalyst to degrade the Black-T in textile [27]. Previous studies basically worked on the issue of SS conditioning, SS dewatering and heavy metal reduction in SS by Fenton's reagent. However, the application of the Fenton method for the removal of organic matter in SS has seldom been investigated.

In the present work, the feasibility of removing organic matter in SS at room temperature through the Fenton method was investigated. The effect of operational parameters, including the concentration and ratio of Fenton's reagent, initial $\mathrm{pH}$ value, reaction time [28], on the removal of organic matter in SS was proposed. 


\section{Materials and Methods}

\subsection{Materials}

A SS sample (TS $=3124 \mathrm{mg} / \mathrm{L}$, VSS $=2480 \mathrm{mg} / \mathrm{L}$ ) obtained from the Dihua Sewage Treatment Plant in Taipei City, Taiwan was used in this study. The as-received SS sample was dewatered by a belt press dehydrator and dried by an indirect heating dryer at $105^{\circ} \mathrm{C}$ in the SS treatment unit of this treatment plant for the purpose of reducing the volume of the produced SS. The main elements in the as-received SS sample are shown in Table 1 which was determined by using $\mathrm{X}$-ray fluorescence spectroscopy (XRF) (SEA6000VX, TechMax). Hydrogen peroxide solution $\left(\mathrm{H}_{2} \mathrm{O}_{2}, 35 \mathrm{wt} \%\right.$ ) (MERU Ltd., Taiwan) and ferrous sulfate $\left(\mathrm{FeSO}_{4} \cdot 7 \mathrm{H}_{2} \mathrm{O}\right)$ (J.T Baker, USA) were used in Fenton experiments.

Table 1. Main elements in the as-received sewage sludge (SS) sample.

\begin{tabular}{ccccccc}
\hline Element & $\mathbf{C u}$ & $\mathbf{C r}$ & $\mathbf{B a}$ & $\mathrm{Al}$ & $\mathbf{S i}$ & $\mathbf{F e}$ \\
\hline content $(\mathrm{wt} \%)$ & 0.41 & 0.28 & 1.2 & 11.6 & 27.1 & 20.8 \\
\hline
\end{tabular}

\subsection{Methods}

The SS sample was first dried in an oven at $105^{\circ} \mathrm{C}$ for $24 \mathrm{~h}$. After drying, $5 \mathrm{~g}$ SS was put into a $1000 \mathrm{ml}$ beaker and mixed with $200 \mathrm{ml}$ distilled water and then stirred with a magnetic mixer for $1 \mathrm{~h}$. The initial $\mathrm{pH}$ was adjusted to the decided value with $0.1 \mathrm{M}$ hydrochloric acid $(\mathrm{HCl})$ and $0.1 \mathrm{M}$ sodium hydroxide $(\mathrm{NaOH})$. The detailed operating procedure of the Fenton method was described in a number of researches [29-31] and the equations are shown in Equations (1)-(3). After adding $\mathrm{FeSO}_{4} \cdot 7 \mathrm{H}_{2} \mathrm{O}$ as catalyst and stirred in a magnetic mixer for 15 mins, $\mathrm{H}_{2} \mathrm{O}_{2}$ was added to activate the reaction. The experimental $\mathrm{pH}$ range was $3,5,7,8$, 9. The $\mathrm{H}_{2} \mathrm{O}_{2}$ dosages of $1.03 \mathrm{M}, 2.06 \mathrm{M}, 3.09$ $\mathrm{M}, 4.12 \mathrm{M}$, and $5.15 \mathrm{M}$, the $\mathrm{Fe}^{2+}$ dosages of $1.72 \mathrm{mM}, 2.06 \mathrm{mM}, 2.58 \mathrm{mM}, 3.43 \mathrm{mM}$, and $5.15 \mathrm{mM}$, the $\left[\mathrm{H}_{2} \mathrm{O}_{2}\right] /\left[\mathrm{Fe}^{2+}\right]$ molar ratios of 1000, 1500, 2000, 2500, and 3000, and the reaction time of $0.5 \mathrm{~h}$, $1 \mathrm{~h}, 2 \mathrm{~h}, 4 \mathrm{~h}, 8 \mathrm{~h}, 24 \mathrm{~h}$, and $48 \mathrm{~h}$ were tested. After the reaction was completed, the solid-liquid separation was conducted using a centrifuge (Tabletop Centrifuge Model 4000, KUBOTA Corp, Japan) at $3500 \mathrm{rpm}$ for $10 \mathrm{mins}$. The solid fraction was dried in an oven at $105^{\circ} \mathrm{C}$ for $24 \mathrm{~h}$ to determine the moisture content. The metal contents in the solid fraction after being dissolved by aqua regia as well as in the liquid fraction were quantitatively analyzed by Induced Coupled Plasma-Optical Emission Spectrometer (ICP-OES, Optima 8300, Perkin Elmer, USA). The thermogravimetric analysis of SS was determined by Thermogravimetry/Differential Thermal Analyzer [32] (TG/DTA) (HITACHI, STA7300, Japan). The heating and combustion treatments were carried out in a muffle furnace (KO TSAO Ltd., Taiwan). The $\mathrm{H}_{2} \mathrm{O}_{2}$ concentration was analyzed by colorimetric determination [33] with a potassium permanganate redox titration method [34] between $470-520 \mathrm{~nm}$ using a spectrophotometer (DR-4000, $\mathrm{HACH}, \mathrm{USA}$ ). Each experiment in this study was performed at least three replicates. The mean value and standard deviation were calculated and plotted.

$$
\begin{gathered}
\mathrm{Fe}^{2+}+\mathrm{H}_{2} \mathrm{O}_{2} \rightarrow \mathrm{Fe}^{3+}+\mathrm{HO} \bullet+\mathrm{OH}^{-} \\
\mathrm{Fe}^{3+}+\mathrm{H}_{2} \mathrm{O}_{2} \rightarrow \mathrm{Fe}^{2+}+\mathrm{HOO} \bullet+\mathrm{H}^{+} \\
2 \mathrm{H}_{2} \mathrm{O}_{2} \rightarrow \mathrm{HO} \bullet+\mathrm{HOO} \bullet+\mathrm{H}_{2} \mathrm{O}
\end{gathered}
$$

\section{Results}

Initially, the TG/DTA analysis was applied to determine the thermal characteristics of SS. The results are shown in Figure 1. With the increase of temperature, the weight of SS gradually decreased. In addition, the strongest exothermic peak appeared at about to $600^{\circ} \mathrm{C}$. Therefore, $600{ }^{\circ} \mathrm{C}$ was chosen as the temperature to determine the removal of organic matter in SS. In the Fenton experiments, a single-factor experiment was firstly applied to obtain the optimal reaction time. Then, 
an experimental design was applied to evaluate the effects of the other four variables (initial $\mathrm{pH}, \mathrm{Fe}^{2+}$, $\left.\mathrm{H}_{2} \mathrm{O}_{2},\left[\mathrm{H}_{2} \mathrm{O}_{2}\right] /\left[\mathrm{Fe}^{2+}\right]\right)$, as shown in Table 2 .

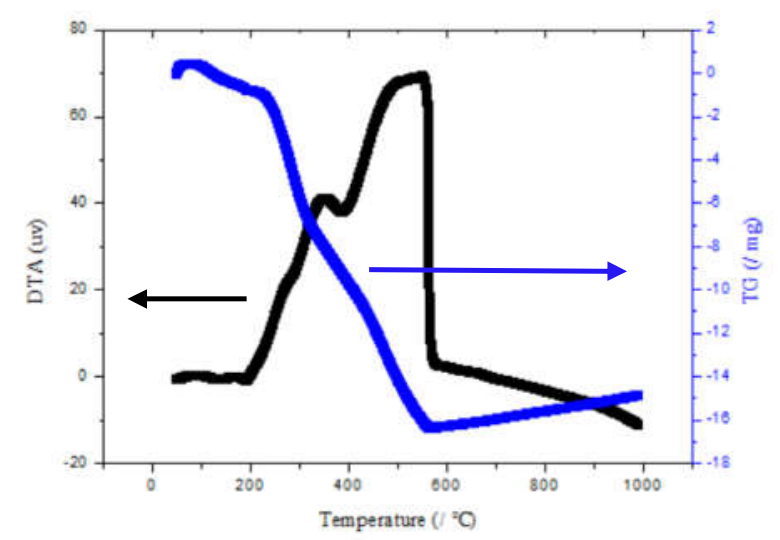

Figure 1. Thermogravimetry/differential thermal analyzer TG/DTA analysis of SS.

Table 2. Factors and levels of the experimental design.

\begin{tabular}{cccccc}
\hline \multirow{2}{*}{ Factors } & \multicolumn{5}{c}{ Levels } \\
\cline { 2 - 6 } & i & ii & iii & iv & v \\
\hline $\mathrm{pH}$ & 3 & 5 & 7 & 8 & 9 \\
\hline $\mathrm{H}_{2} \mathrm{O}_{2}(\mathrm{M})$ & 1.03 & 2.06 & 3.09 & 4.12 & 5.15 \\
\hline $\mathrm{Fe}^{2+}(\mathrm{mM})$ & 1.72 & 2.06 & 2.58 & 3.43 & 5.15 \\
\hline$\left[\mathrm{H}_{2} \mathrm{O}_{2}\right] /\left[\mathrm{Fe}^{2+}\right]$ & 1000 & 1500 & 2000 & 2500 & 3000 \\
\hline
\end{tabular}

\subsection{The Effect of Initial $p H$ Value}

The effect of initial $\mathrm{pH}$ value on the removal of organic matter is shown in Figure 2. Under the experimental conditions of a fixed molar ratio $\left[\mathrm{H}_{2} \mathrm{O}_{2}\right] /\left[\mathrm{Fe}^{2+}\right]$ of 1000 and variable $\mathrm{H}_{2} \mathrm{O}_{2}$ concentrations, the removal of organic matter increased with the increase in initial $\mathrm{pH}$ value from $\mathrm{pH} 3-7$. A maximum removal of $79.1 \%$ was obtained at $\mathrm{pH} 7$ with the dosage of $5.15 \mathrm{M} \mathrm{H}_{2} \mathrm{O}_{2}$. The data are also presented in Table 3. By contrast, it was observed that at $\mathrm{pH}$ values of 8 and 9 , the effectiveness of $\mathrm{pH}$ on the removal fraction gradually decreased with the increase in $\mathrm{H}_{2} \mathrm{O}_{2}$ concentration. Consequently, the optimal initial $\mathrm{pH}$ value was considered to be $\mathrm{pH} 7$.

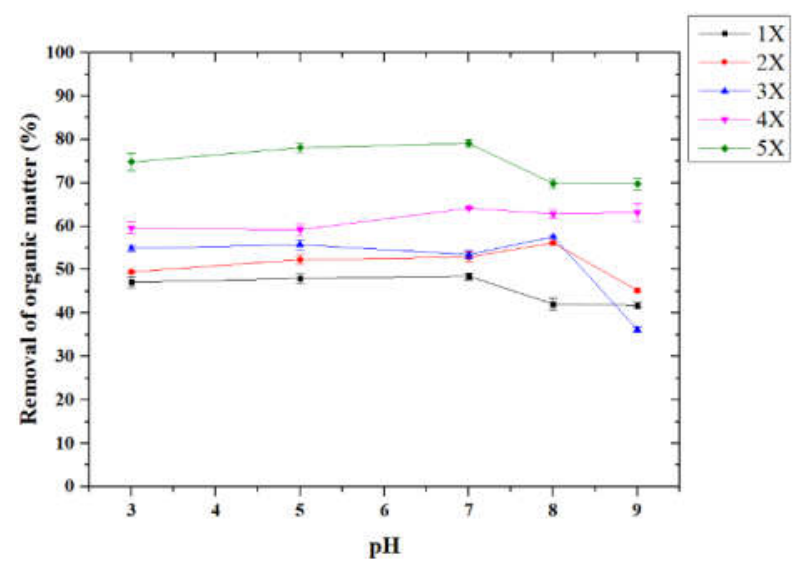

Figure 2. The effect of initial $\mathrm{pH}$ value on the removal of organic matter (Experimental conditions: $1 \mathrm{X}$ $5 X$ indicate the dosage of $\mathrm{H}_{2} \mathrm{O}_{2}$ from $1.03 \mathrm{M} \sim 5.15 \mathrm{M}$, molar ratio $\left[\mathrm{H}_{2} \mathrm{O}_{2}\right] /\left[\mathrm{Fe}^{2+}\right]$ of 1000 , reaction time of $3 \mathrm{~h}, 5 \mathrm{~g}$ SS in $200 \mathrm{ml}$ distilled water). 
Table 3. The removal of organic matter at different initial $\mathrm{pH}$ values and $\mathrm{H}_{2} \mathrm{O}_{2}$ dosages.

\begin{tabular}{cccccc}
\hline \multicolumn{5}{c}{ Removal of Organic Matter (\%) } \\
\hline \multirow{2}{*}{$\mathbf{p H}$} & $\mathbf{1 . 0 3} \mathbf{M}$ & $\mathbf{2 . 0 6} \mathbf{M}$ & $\mathbf{3 . 0 9} \mathbf{M}$ & $\mathbf{4 . 1 2} \mathbf{M}$ & $\mathbf{5 . 1 5} \mathbf{~}$ \\
\cline { 2 - 6 } & $47.1 \pm 1.2$ & $49.5 \pm 0.3$ & $54.9 \pm 0.7$ & $59.6 \pm 1.4$ & $74.8 \pm 2.0$ \\
\hline 3 & $48.0 \pm 1.1$ & $52.3 \pm 1.1$ & $55.8 \pm 1.1$ & $59.2 \pm 1.3$ & $78.1 \pm 1.2$ \\
\hline 5 & $48.5 \pm 0.8$ & $52.9 \pm 1.2$ & $53.5 \pm 0.8$ & $64.2 \pm 0.2$ & $79.1 \pm 0.9$ \\
\hline 7 & $42.1 \pm 1.3$ & $56.2 \pm 0.5$ & $57.6 \pm 1.3$ & $62.9 \pm 0.9$ & $69.9 \pm 1.1$ \\
\hline 8 & $41.8 \pm 1.6$ & $45.2 \pm 0.6$ & $36.2 \pm 1.6$ & $63.2 \pm 2.0$ & $69.8 \pm 1.3$ \\
\hline 9 & & & & &
\end{tabular}

\subsection{The Effect of $\mathrm{H}_{2} \mathrm{O}_{2}$ Dosage}

The effect of $\mathrm{H}_{2} \mathrm{O}_{2}$ dosage on the removal of organic matter and the organic/inorganic fraction is shown in Figure 3. With the increase in $\mathrm{H}_{2} \mathrm{O}_{2}$ dosage, the removal of organic matter increased. In addition, the organic fraction decreased whereas the inorganic fraction increased, which implied the removal of organic matter. When the $\mathrm{H}_{2} \mathrm{O}_{2}$ dosage was higher than $4.12 \mathrm{M}$, the removal of organic matter and the organic/inorganic fraction had no significant change. The removal of organic matter reached $29.5 \%$ when the $\mathrm{H}_{2} \mathrm{O}_{2}$ dosage was $5.15 \mathrm{M}$. In addition, the organic and inorganic fraction were almost the same (50.4\% and $49.6 \%$, respectively).

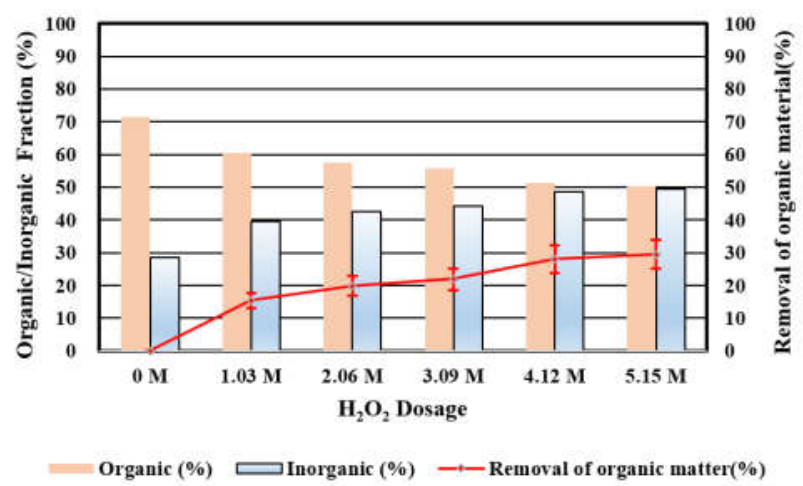

Figure 3. The effect of $\mathrm{H}_{2} \mathrm{O}_{2}$ dosage on the removal of organic matter and the organic/inorganic fraction (Experimental conditions: the dosage of $\mathrm{H}_{2} \mathrm{O}_{2}$ was prepared by diluting the $35 \mathrm{wt} \% \mathrm{H}_{2} \mathrm{O}_{2}$ solution, reaction time of $3 \mathrm{~h}, \mathrm{pH} \mathrm{7,5 \textrm {g } S \mathrm { in }} 200 \mathrm{ml}$ distilled water).

\subsection{The Effect of $\left[\mathrm{H}_{2} \mathrm{O}_{2}\right] /\left[\mathrm{Fe}^{2+}\right]$ Molar Ratio}

The effect of $\left[\mathrm{H}_{2} \mathrm{O}_{2}\right] /\left[\mathrm{Fe}^{2+}\right]$ molar ratio on the removal of organic matter and the organic/inorganic fraction is shown in Figure 4. When the $\mathrm{H}_{2} \mathrm{O}_{2}$ dosage was fixed at $5.15 \mathrm{M}$, the removal of organic matter increased with the decrease in $\left[\mathrm{H}_{2} \mathrm{O}_{2}\right] /\left[\mathrm{Fe}^{2+}\right]$ molar ratio from 3000 to 1000 . In addition, the organic fraction decreased whereas the inorganic fraction increased, which implied the removal of organic matter. The removal of organic matter achieved $77.2 \%$ when the $\mathrm{Fe}^{2+}$ dosage was $5.15 \mathrm{mM}$ and the $\left[\mathrm{H}_{2} \mathrm{O}_{2}\right] /\left[\mathrm{Fe}^{2+}\right]$ molar ratio was 1000 . Meanwhile, the organic and inorganic fraction was $16.3 \%$ and $83.7 \%$, respectively. The difference between the organic and inorganic fraction reached a maximum level. 


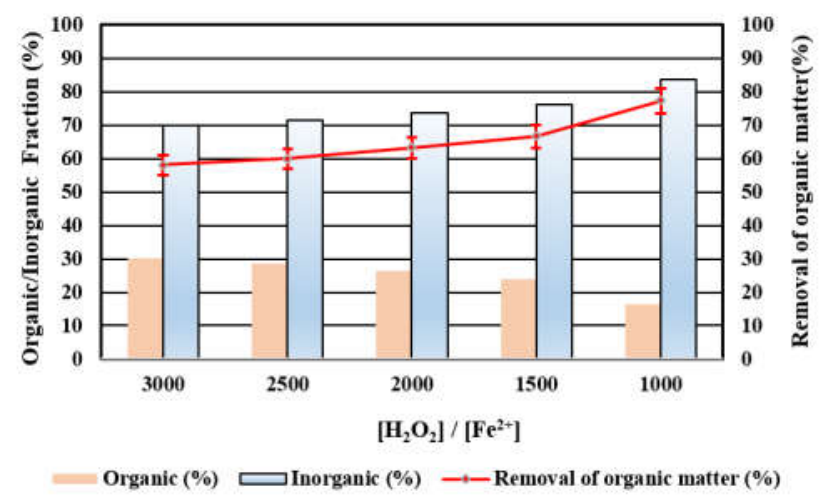

Figure 4. The effect of $\left[\mathrm{H}_{2} \mathrm{O}_{2}\right] /\left[\mathrm{Fe}^{2+}\right]$ molar ratio on the removal of organic matter and the organic/inorganic fraction (Experimental conditions: the dosage of $\mathrm{H}_{2} \mathrm{O}_{2}$ was fixed at $5.15 \mathrm{M}$, the dosage of $\mathrm{Fe}^{2+}$ was $1.72-5.15 \mathrm{mM}$, reaction time of $3 \mathrm{~h}, \mathrm{pH} 7,5 \mathrm{~g}$ SS in $200 \mathrm{ml}$ distilled water).

\subsection{The Effect of Reaction Time}

The effect of reaction time on the removal of organic matter is shown in Figure 5. With the dosages of $5.15 \mathrm{M} \mathrm{H}_{2} \mathrm{O}_{2}$ and $5.15 \mathrm{mM} \mathrm{Fe}^{2+}$ at $\mathrm{pH} 7$, the removal of organic matter increased with reaction time until $2 \mathrm{~h}$. There is no significant change in the removal of organic matter after $2 \mathrm{~h}$. The maximum removal of organic matter $83.7 \%$ was reached at $2 \mathrm{~h}$.

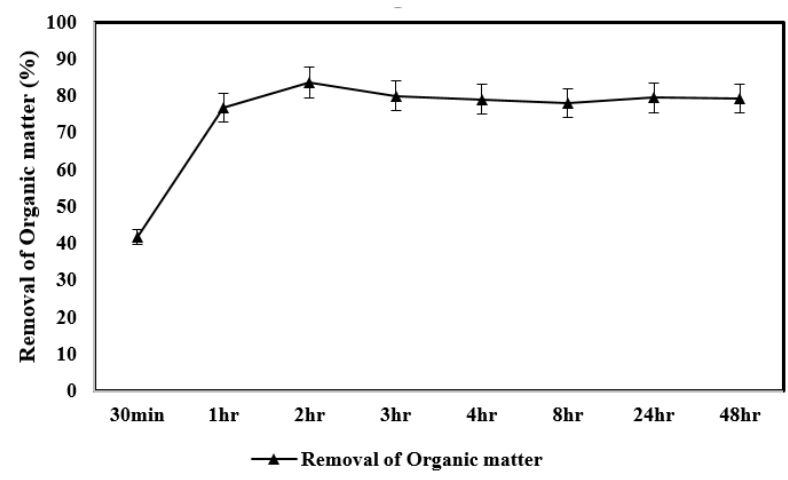

Figure 5. The effect of reaction time on the removal of organic matter (Experimental conditions: $\mathrm{H}_{2} \mathrm{O}_{2}$ dosage $5.15 \mathrm{M}, \mathrm{Fe}^{2+}$ dosage $5.15 \mathrm{mM}, \mathrm{pH}$ 7, $5 \mathrm{~g}$ SS in $200 \mathrm{ml}$ distilled water).

\subsection{The Hevay Metal Content in the Solid Fraction after Fenton Treatment}

According to the above experimental results, the optimal conditions for the removal of organic matter in $\mathrm{SS}$ by the Fenton method were $\mathrm{H}_{2} \mathrm{O}_{2}$ dosage of $5.15 \mathrm{M}, \mathrm{Fe}^{2+}$ dosage of $5.15 \mathrm{mM}$, reaction time of $2 \mathrm{~h}$, and $\mathrm{pH} 7$. Under these conditions, the maximum organic matter removal of $83.7 \%$ was obtained. On the other hand, the heavy metal content in the solid fraction obtained from the aforementioned optimal Fenton treatment conditions is shown in Table 4. The main heavy metal elements in the SS after Fenton treatment were $\mathrm{Si}(18.4 \mathrm{wt} \%)$ and $\mathrm{Al}(39.4 \mathrm{wt} \%)$, which was suitable to be an ideal raw material for the synthesis of geopolymer. On the other hand, Zhu et al. reported that $75.3 \%$ of Cu in SS was removed after Fenton treatment [26]. In this work, the removal of Cu in SS was 79.1\%, which was similar to Zhu et al.'s result. The effectiveness of heavy metal reduction in SS after Fenton treatment was also confirmed. 
Table 4. The hevay metal content in the solid fraction after Fenton treatment (X-ray fluorescence spectroscopy (XRF) values) (Experimental conditions: $\mathrm{H}_{2} \mathrm{O}_{2}$ dosage $5.15 \mathrm{M}, \mathrm{Fe}^{2+}$ dosage $5.15 \mathrm{mM}, \mathrm{pH}$ $7,5 \mathrm{~g}$ SS in $200 \mathrm{ml}$ distilled water).

\begin{tabular}{ccccccc}
\hline Elements & $\mathbf{C u}$ & $\mathbf{C r}$ & $\mathbf{B a}$ & $\mathrm{Al}$ & $\mathrm{Si}$ & $\mathbf{F e}$ \\
\hline $\mathrm{Wt} \%$ & 0.32 & 0.26 & 1.17 & 39.4 & 18.4 & 40.5 \\
\hline
\end{tabular}

\section{Discussion}

In this section, several parameters involved in Fenton reaction, including the initial $\mathrm{pH}$ value, molar ratio of Fenton's reagent $\left(\left[\mathrm{Fe}^{2+}\right] /\left[\mathrm{H}_{2} \mathrm{O}_{2}\right]\right)$, reaction time, heavy metal reduction, and organic matter removal were discussed.

According to the theory of Fenton reaction [35], an increase in $\mathrm{pH}$ not only inhibits the production of $\mathrm{OH} \cdot$ radical, but also causes the precipitation of $\mathrm{Fe}^{2+}$ in the solution which loses the catalytic ability of $\mathrm{Fe}^{2+}$. Generally, Fenton reaction has a high degradation efficiency at an initial $\mathrm{pH}$ of 3 in wastewater treatment. Different from wastewater treatment, however, it is reported that the initial $\mathrm{pH}$ value within 2-7 has no significant effect on the efficiency of oxidation when applying Fenton treatment for SS [20-22]. In this work, a phenomenon was observed that no matter what the initial $\mathrm{pH}$ values were within $\mathrm{pH} 3-9$, the final $\mathrm{pH}$ values after Fenton treatment were almost within $\mathrm{pH} 1-2$. It might be caused by the decomposition of the long-chain organic matter by the $\mathrm{OH}$ - radical, which released the short-chain organic acid and thus lowered the final $\mathrm{pH}$ values. Therefore, the initial $\mathrm{pH}$ value has no significant effect on the removal of organic matter in SS. When applying the Fenton method in the field of wastewater treatment, it is necessary to conduct the pre-acidification treatment to reduce the initial $\mathrm{pH}$ value to 3 in order to improve the Fenton reaction [35]. However, when the Fenton method was applied for the dehydration of SS, the initial $\mathrm{pH}$ value did not significantly affect the dewaterability [20-22]. According to the experimental results obtained in this work, there was no significant difference in the removal of organic matter in SS at an initial pH value of 3-7. Therefore, when applying the Fenton method for the organic matter removal in SS at an initial pH value between $3-7$, no pre-acidification treatment is needed, which might reduce the operation cost. By contrast, the organic matter removal decreased when the initial $\mathrm{pH}$ value was higher than 8 . It is considered that the $\mathrm{Fe}^{2+}$ precipitated at $\mathrm{pH}$ value higher than 8 , which led to the decrease of the catalystic ability of $\mathrm{Fe}^{2+}$.

In this work, it was also observed that a small fraction of the organic matter could be removed without $\mathrm{Fe}^{2+}$ addition. It is also reported that the ferrous ion in SS was capsulated by the organic matter [19]. Therefore, the Fenton reaction could also occur slightly without the addition of $\mathrm{Fe}^{2+}$ reagent only through the $\mathrm{H}_{2} \mathrm{O}_{2}$ addition. $\mathrm{Yu}$ et al. investigated the performance of SS conditioning of several methods, including Fenton-like reaction, Fenton reaction, $\mathrm{FeSO}_{4}, \mathrm{FeCl}_{3}$, and $\mathrm{H}_{2} \mathrm{O}_{2}$ [24]. Dewaterability was observed with the addition of $34.3 \mathrm{mg} / \mathrm{g} \mathrm{DS} \mathrm{H}_{2} \mathrm{O}_{2}$ and the initial $\mathrm{pH}$ at 3 but without $\mathrm{Fe}^{2+}$ addition.

The molar ratio of Fenton's reagent $\left(\left[\mathrm{Fe}^{2+}\right] /\left[\mathrm{H}_{2} \mathrm{O}_{2}\right]\right)$ should be a significant parameter in the Fenton reaction. Katsiris et al. reported that the molar ratio of $\left[\mathrm{Fe}^{2+}\right] /\left[\mathrm{H}_{2} \mathrm{O}_{2}\right]$ was much less than 1 in the Fenton reaction using $\mathrm{Fe}^{2+}$ as the catalyst [36]. Once the molar ratio of $\left[\mathrm{Fe}^{2+}\right] /\left[\mathrm{H}_{2} \mathrm{O}_{2}\right]$ was close to 1, a large amount of $\mathrm{Fe}^{2+}$ would convert to $\mathrm{Fe}^{3+}$ which might stop the reaction. $\mathrm{The} \mathrm{Fe}^{3+}$ would become a coagulant to enhance SS dewaterability. In this work, the optimal molar ratio of $\left[\mathrm{Fe}^{2+}\right] /\left[\mathrm{H}_{2} \mathrm{O}_{2}\right]$ was 0.001 . Therefore, the $\mathrm{Fe}^{2+}$ could certainly retain the effectiveness of Fenton reaction. Fishbacher et al. reported that among the molar ratio of $\left[\mathrm{H}_{2} \mathrm{O}_{2}\right] /\left[\mathrm{Fe}^{2+}\right]=1000,100,50,25,10$, the molar ratio $\left[\mathrm{H}_{2} \mathrm{O}_{2}\right] /\left[\mathrm{Fe}^{2+}\right]$ of 1000 had the best productivity of $\mathrm{HO}$. radical [37], which was consistent with the optimal molar ratio conditions in this work.

About the reaction time of the Fenton method, Liu et al. also proposed a 60 min reaction time for Fenton reaction pretreatment [22]. Neyens et al. reported that the reaction time of applying the Fenton reaction for SS conditioning was $60 \mathrm{mins}$ [18]. Yu et al. mentioned about the stirring time 30 mins 
for the Fenton-like reaction in the SS conditioning process [24]. These researches had similar reaction times of 30-60 mins in the field of SS conditioning. In this work, the optimal reaction time for the removal of organic matter in SS was $2 \mathrm{~h}$. Therefore, the optimal reaction time depends on the purpose of SS treatment. However, the Fenton reaction could ideally be finished in $2 \mathrm{~h}$.

About the issue that SS was a hazardous material because of the heavy metal contents, it has been reported that the Fenton method has the effectiveness of breaking SS to release heavy metal components [24,25]. This helps to reduce the heavy metals in SS after organic matter removal by Fenton treatment. Meanwhile, when the SS is used for subsequent geopolymer synthesis, the synthesized geopolymer has the characteristic of immobilizing the heavy metals in the aggregated structure. Therefore, it is considered that the geopolymer synthesis can ideally solve the problems of heavy metals in SS. The synthesis of geopolymer using the SS after organic matter removal by Fenton treatment will be dealt with separately.

Compared to other studies that investigated the dewaterability of SS or the release of EPS by the Fenton method, this study confirmed the effectiveness of the Fenton method on the removal of organic matter in SS. In addition, this study also confirmed that without applying high temperature incineration, the organic matter in SS can be effectively removed at room temperature by the Fenton method. The SS after Fenton treatment can be used as raw material for geopolymer synthesis also at room temperature, which makes the synthesis of geopolymer using SS possess higher environmental benefits of energy saving and carbon reduction compared to the overall production process of cement.

\section{Conclusions}

In this study, the Fenton method was applied to remove the organic matter in SS at room temperature. The effects of operational parameters in the Fenton method on the removal of organic matter in SS were studied. The following results were obtained:

(1) The optimal conditions for the removal of organic matter in SS by the Fenton method were $\mathrm{H}_{2} \mathrm{O}_{2}$ dosage of $5.15 \mathrm{M}, \mathrm{Fe}^{2+}$ dosage of $5.15 \mathrm{mM}$, reaction time of $2 \mathrm{~h}$, and $\mathrm{pH}$ 7. Under these conditions, the maximum organic matter removal of $83.7 \%$ was obtained.

(2) The initial $\mathrm{pH}$ between 3-7 had no significant influence on the removal of organic matter in SS. The optimal molar ratio of $\left[\mathrm{H}_{2} \mathrm{O}_{2}\right] /\left[\mathrm{Fe}^{2+}\right]$ for the organic matter removal was 1000 .

(3) The main heavy metal elements in the SS after Fenton treatment were Si (18.4 wt \%) and Al (39.4 $\mathrm{wt} \%)$, which are suitable to be ideal raw material for the synthesis of geopolymer.

Author Contributions: Conceptualization, T.-W.C.; methodology, S.-S.C.; investigation, Y.-J.C. and T.-Y.F.; writing-original draft preparation, Y.-J.C. and T.-Y.F.; writing-review and editing, L.-P.W. and S.C.; supervision, L.-P.W. and S.C.; project administration, L.-P.W.; funding acquisition, L.-P.W., M.-H.Y. and S.C. All authors have read and agreed to the published version of the manuscript.

Funding: This study was financially supported in part by the R.O.C. Ministry of Science and Technology under Grant Nos. MOST 108-2221-E-027-079- and NTUT-USTB Joint Research Program under Grant Nos. TW201704 and NTUT-USTB-106-06.

Conflicts of Interest: The authors declare no conflict of interest.

\section{References}

1. Zhang, J.; Liu, G.; Chen, B.; Song, D.; Qi, J.; Liu, X. Analysis of $\mathrm{CO}_{2}$ Emission for the Cement Manufacturing with Alternative Raw Materials: A LCA-based Framework. Energy Procedia 2014, 61, 2541-2545. [CrossRef]

2. Merabtene, M.; Kacimi, L.; Clastres, P. Elaboration of geopolymer binders from poor kaolin and dam sludge waste. Heliyon 2019, 5, e01938. [CrossRef]

3. Kumar, S.; Kumar, R.; Mehrotra, S.P. Influence of granulated blast furnace slag on the reaction, structure and properties of fly ash based geopolymer. J. Mater. Sci. 2010, 45, 607-615. [CrossRef]

4. Tchakoute, K.H.; Elimbi, A.; Mbey, J.A.; Ngally, S.C.J.; Njopwouo, D. The effect of adding alumina-oxide to metakaolin and volcanic ash on geopolymer products: A comparative study. Constr. Build. Mater. 2012, 35, 960-969. [CrossRef] 
5. Somna, K.; Jaturapitakkul, C.; Kagitvichyanukul, P.; Chindaprasirt, P. NaOH-activated ground fly ash geopolymer cured at ambient temperature. Fuel 2011, 90, 2118-2124. [CrossRef]

6. Chen, J.H.; Huang, J.S.; Chang, Y.W. A preliminary study of reservoir sludge as a raw material of inorganic polymers. Constr. Build. Mater. 2009, 23, 3264-3296. [CrossRef]

7. Gherghel, A.; Teodosiu, C.; De Gisi, S. A review on wastewater sludge valorisation and its challenges in the context of circular economy. J. Clean. Prod. 2019, 228, 244-263. [CrossRef]

8. Tyagi, V.K.; Lo, S.L. Sludge: A waste or renewable source for energy and resources recovery. Renew. Sustain. Energy Rev. 2013, 25, 708-728. [CrossRef]

9. Nidheesh, P.V.; Rajan, R. Removal of rhodamine B from a water medium using hydroxyl and sulphate radicals generated by iron loaded activated carbon. RSC Adv. 2016, 6, 5330-5340. [CrossRef]

10. Xavier, S.; Gandhimathi, R.; Nidheesh, P.V.; Ramesh, S.T. Comparison of homogeneous and heterogeneous Fenton processes for the removal of reactive dye Magenta MB from aqueous solution. Desalin. Water Treat. 2015, 53, 109-118. [CrossRef]

11. Alalm, M.G.; Tawfik, A.; Ookawara, S. Degradation of four pharmaceuticals by solar photo-Fenton process: Kinetics and costs estimation. J. Environ. Chem. Eng. 2015, 3, 46-51. [CrossRef]

12. Mackul'ak, T.; Mosn’y, M.; Grabic, R.; Golovko, O.; Koba, O.; Biro`sová, L. Fenton-like reaction: A possible way to efficiently remove illicit drugs and pharmaceuticals from wastewater. Environ. Toxicol. Pharm. 2015, 39, 483-488. [CrossRef] [PubMed]

13. Aytar, P.; Gedikli, S.; Sam, M.; Farizo`glu, B.; Cabuk, A. Sequential treatment of olive oil mill wastewater with adsorption and biological and photo-Fenton oxidation. Envirron. Sci. Pollut. Res. 2013, 20, 3060-3067. [CrossRef] [PubMed]

14. Justino, C.; Marques, A.G.; Duarte, K.R.; Duarte, A.C.; Pereira, R.; Rocha-Santos, T. Freitas, Degradation of phenols in olive oil mill wastewater by biological, enzymatic, and photo-Fenton oxidation. Environ. Sci. Pollut. Res. 2010, 17, 650-656. [CrossRef] [PubMed]

15. Laiju, A.R.; Sivasankar, T.; Nidheesh, P.V. Iron-loaded mangosteen as a heterogeneous Fenton catalyst for the treatment of landfill leachate. Environ. Sci. Pollut. Res. 2014, 21, 10900-10907. [CrossRef] [PubMed]

16. Navarro, S.; Fenoll, J.; Vela, N.; Ruiz, E.; Navarro, G. Removal of ten pesticides from leaching water at pilot plant scale by photo-Fenton treatment. Chem. Eng. J. 2011, 167, 42-49. [CrossRef]

17. Saini, R.; Raghunath, C.V.; Pandey, P.; Kumar, P. Optimization of Fenton oxidation for the removal of methyl parathion in aqueous solution. Perspect. Sci. 2016, 1980, 670-672. [CrossRef]

18. Neyens, E.; Baeyens, J.; Weemaes, M.; De hyder, B. Pilot-scale peroxidation $\left(\mathrm{H}_{2} \mathrm{O}_{2}\right)$ of sewage sludge. J. Hazard. Mater. 2003, 98, 91-106. [CrossRef]

19. Neyens, E.; Baeyens, J.; Dewil, R.; De hyder, B. Advanced sludge treatment affects extracellular polymeric substances to improve activated sludge dewatering. J. Hazard. Mater. 2004, 106, 83-92. [CrossRef]

20. Lu, M.; Lin, C.; Liao, C.; Ting, W.; Huang, R. Influence of $\mathrm{pH}$ on the dewatering of activated sludge by Fenton's reagent. Water Sci. Technol. 2001, 44, 327-332. [CrossRef]

21. Tony, M.A.; Zhao, Y.Q.; Tayeb, A.M. Exploitation of Fenton and Fenton-like reagents as alternative conditioners for alum sludge conditioning. J. Environ. Sci. China 2009, 21, 101-105. [CrossRef]

22. Liu, H.; Yang, J.; Shi, Y.; Li, Y.; He, S.; Yang, C.; Yao, H. Conditioning of sewage sludge by Fenton's reagent combined with skeleton builders. Chemosphere 2012, 88, 235-239. [CrossRef] [PubMed]

23. Liu, H.; Liu, P.; Hu, H.; Zhang, Q.; Wu, Z.; Yang, J.; Yao, H. Combined effects of Fenton peroxidation and $\mathrm{CaO}$ conditioning on sewage sludge thermal drying. Chemosphere 2014, 117, 559-566. [CrossRef] [PubMed]

24. Yu, W.; Yang, J.; Shi, Y.; Song, J.; Shi, Y.; Xiao, J.; Li, C.; Xu, X.; He, S.; Liang, S.; et al. Roles of iron species and $\mathrm{pH}$ optimization on sewage sludge conditioning with Fenton's reagent and lime. Water Res. 2016, 95, 124-133. [CrossRef]

25. Dewil, R.; Baeyens, J.; Appels, L. Enhancing the use of waste activated sludge as bio-fuel through selectively reducing its heavy metal content. J. Hazard. Mater. 2007, 144, 703-707. [CrossRef]

26. Zhu, Y.; Zeng, G.; Zhang, P.; Zhang, C.; Ren, M.; Zhang, J.; Chen, M. Feasibility of bioleaching combined with Fenton-like reaction to remove heavy metals from sewage sludge. Bioresour. Technol. 2013, 142, 530-534. [CrossRef]

27. Wen, H.; Lin, G.; Yu, H.; Qiao, X.; Zhang, D.; Ye, J. Radical assisted iron impregnation on preparing sewage sludge derived Fe/carbon as highly stable catalyst for heterogeneous Fenton reaction. Chem. Eng. J. 2018, 352, 837-846. [CrossRef] 
28. Mustapha Mohammed, B.; Abdul Aziz, A.R.; Anam, A. A review on approaches for addressing the limitations of Fenton oxidation for recalcitrant wastewater treatment. Process Saf. Environ. 2019, 126, 119-140.

29. Haber, F.; Weiss, J. On the catalysis of hydroperoxides. Naturwissenschaften 1932, 20, 948-950. [CrossRef]

30. Fenton, H.J.H. Oxidation of tartaric acid in presence of iron. J. Chem. Soc. Trans. 1894, 65, 899-911. [CrossRef]

31. Koppenol, W.H. The centennial of the Fenton reaction. Free Radic. Biol. Med. 1993, 15, 645-651. [CrossRef]

32. Coats, A.W.; Redfern, J.P. Thermogravimetric Analysis: A Review. Analyst 1963, 88, 906-924. [CrossRef]

33. Greenan, N.S.; Mulvaney, R.L.; Sims, G.K. A microscale method for colorimetric determination of urea in soil extracts. Commun. Soil Sci. Plant Anal. 1995, 26, 2519-2529. [CrossRef]

34. Lee, H.L. CN. 103712930A. 2016. Available online: https://patentimages.storage.googleapis.com/f1/7b/b7/ 8f4603eaa51880/CN103712930A.pdf (accessed on 18 February 2020).

35. Walling, C. Fenton's reagent revisited. Acc. Chem. Res. 1975, 8, 125-131. [CrossRef]

36. Katsiris, N.; Kouzeli-Katsiri, A. Bound water content of biological sludges in relation to filtration and dewatering. Water Res. 1987, 21, 1319-1327. [CrossRef]

37. Fishbacher, A.; Sonntag, C.V.; Schmidt, T.C. Hydroxyl radical yields in the Fenton process under various $\mathrm{pH}$, ligand concentrations and hydrogen peroxide/Fe(II) ratios. Chemosphere 2017, 182, 738-744. [CrossRef]

(C) 2020 by the authors. Licensee MDPI, Basel, Switzerland. This article is an open access article distributed under the terms and conditions of the Creative Commons Attribution (CC BY) license (http://creativecommons.org/licenses/by/4.0/). 